\title{
Management of the trigeminocardiac reflex: Facts and own experience
}

\author{
Belachew Arasho ${ }^{1,4}$, Nora Sandu ${ }^{2}$, Toma Spiriev $^{1}$, Hemanshu Prabhakar ${ }^{3}$, Bernhard Schaller $^{1}$ \\ ${ }^{1}$ Departments of Neurosurgery, University of Paris, France, ${ }^{2}$ University of Lausanne, Switzerland, ${ }^{3}$ Neuroanesthesiology, \\ Neurosciences Center, All India Institute of Medical Sciences, New Delbi, India, ${ }^{4}$ Department of Neurology, Addis Ababa University, Ethiopia
}

Address for correspondence:

Dr. Bernhard Schaller,

Department of Neurosurgery,

University of Paris, France.

E-mail: bernhard.schaller@yahoo.de

DOI: $10.4103 / 0028-3886.55577$

\begin{abstract}
The trigeminocardiac reflex (TCR) is defined as the sudden onset of parasympathetic dysrhythmia, sympathetic hypotension, apnea, or gastric hyper-motility during stimulation of any of the sensory branches of the trigeminal nerve. The proposed mechanism for the development of TCR is - the sensory nerve endings of the trigeminal nerve send neuronal signals via the Gasserian ganglion to the sensory nucleus of the trigeminal nerve, forming the afferent pathway of the reflex arc. It has been demonstrated that the TCR may occur with mechanical stimulation of all the branches of the trigeminal nerve anywhere along its course (central or peripheral). The reaction subsides with cessation of the stimulus. But, some patients may develop severe bradycardia, asystole, and arterial hypotension which require intervention. The risk factors already known to increase the incidence of TCR include: Hypercapnia; hypoxemia; light general anesthesia; age (more pronounced in children); the nature of the provoking stimulus (stimulus strength and duration); and drugs: Potent narcotic agents (sufentanil and alfentanil); betablockers; and calcium channel blockers. Because of the lack of full understanding of the TCR physiology, the current treatment options for patients with TCR include: (i) risk factor identification and modification; (ii) prophylactic measures; and (iii) administration of vagolytic agents or sympathomimetics.
\end{abstract}

Key words: Atropine, cardiac reflex, oculocardiac reflex, skull base surgery, treatment, trigemino

\section{Introduction}

The trigeminal nerve is the largest of the cranial nerves, and it provides sensory supply to the face, scalp, and mucosa of the nose and mouth. ${ }^{[1-3]}$ Stimulation of the trigeminal receptors that innervate the nose and nasal passages is thought to provide an important stimulus for the initiation of the trigeminorespiratory reflex and cardiac arrhythmias which could arise with it. This has been studied in animals and known for more than a century, ${ }^{[4-6]}$ and is now considered as the trigeminocardiac reflex (TCR). In the early $20^{\text {th }}$ century, this TCR has gained much clinical attention, in the form of the oculocardiac reflex (OCR) which is the cardiac response (mainly bradycardia) associated with stimulation of the ophthalmic division of the trigeminal nerve during ocular surgeries. ${ }^{[7,8]}$ Then, Schaller, for the first time, demonstrated that a similar reflex occurs with stimulation of the intracranial portion of the trigeminal nerve. ${ }^{[1]}$ Again Schaller was the first who subsummarized all these reflexes under the term TCR. ${ }^{[2,9]}$ Since then, there has been much discussion about the reflex itself and the prophylaxis and treatment of the TCR when it occurs during intracranial or extracranial procedures. But until now, there exists no clear recommendations how to treat the TCR. So, the aim of the present work is to update knowledge about currently available treatment options for patients with TCR.

\section{Definition and Pathophysiology of the Trigeminocardiac Reflex}

The TCR is defined as the sudden onset of parasympathetic dysrhythmia, sympathetic hypotension, apnea, or 
gastric hyper-motility during stimulation of any of the sensory branches of the trigeminal nerve. ${ }^{[1]}$ The proposed mechanism for the development of the TCR is that the sensory nerve endings of the trigeminal nerve send neuronal signals via the Gasserian ganglion to the sensory nucleus of the trigeminal nerve, forming the afferent pathway of the reflex arc. ${ }^{[1,2]}$ This afferent pathway continues along the short internuncial nerve fibres in the reticular formation to connect with the efferent pathway in the motor nucleus of the vagus nerve. Several lines of experimental evidence demonstrate that trigeminally induced cardiovascular reflexes could be mediated initially in the trigeminal nucleus caudalis and subsequently in the parabrachial nucleus, the rostral ventrolateral medulla oblongata, the dorsal medullary reticular field, and the paratrigeminal nucleus in animal models. ${ }^{[3,10,11]}$

The TCR occurs during both, the peripheral and the central manipulations of the trigeminal nerve. The OCR, which is a subform of the TCR, has long been reported in patients with ocular surgeries and manipulations. ${ }^{[7,8,12]}$ In 1999, Schaller et al., for the first time, reported the occurrence of the TCR in skull base and neurological surgeries. ${ }^{[1]}$ The underlying responsible mechanism is not yet fully understood, but is believed to be the same as the OCR reported earlier on, i.e., activation of the central or intracranial portions of the trigeminal nerve. ${ }^{[2]}$

\section{Epidemiology of the Trigeminocardiac Reflex}

It has been demonstrated that the TCR may occur with manipulation of all the branches of the trigeminal nerve anywhere along its (intracranial or extracranial) course ${ }^{[7,8,12-16]}$ The OCR, which is a subvariant of the TCR, and studied far earlier, was said to occur in up to $67 \%$ of the patients operated for strabismus, ${ }^{[17]}$ but a lot of authors only studied the heart rate and a reduction in heart rate by $10 \%$ or more was taken as a positive OCR, so that the real incidence may be substantially smaller. According to Schaller's experience, the TCR occurs in $10-18 \%$ of the patients. ${ }^{[1,18-20]}$ In a retrospective review of 125 patients operated for tumors of the cerebello-pontine angle, Schaller et al. noticed the occurrence of the TCR in $11 \%$ of the operated patients. ${ }^{[4]}$ Three of the patients in this series developed asystole which lasted from 30-70 seconds. ${ }^{[1]}$ In contrast to the studies on OCR, Schaller take into consideration the heart rate and blood pressure into account and defined TCR as heart rate less than 60 beats per minute and mean arterial blood pressure (MABP) 20\% lower than the baseline. ${ }^{[1]}$

In another study, Schaller also showed the occurrence of TCR during microvascular decompression of the trigeminal nerve for trigeminal neuralgia. ${ }^{[20]}$ In this review on 28 patients, the incidence of TCR was 18\% with the same definition used as in his prior study, i.e., heart rate less than 60 beats per minute and MABP 20\% lower than the baseline. ${ }^{[20]}$ TCR was also reported during transsphenoidal surgery for pituitary adenoma. ${ }^{[9,19,21]}$ Among 117 patients who underwent transsphenoidal surgery for pituitary adenoma, 10\% developed a TCR during the surgical procedure. ${ }^{[19]}$ Peripheral stimulation of the naso-pharynx may also lead to TCR. ${ }^{[9]}$

\section{Risk Factors for Occurrence of the Trigeminocardiac Reflex}

As there is a lack of detailed knowledge of the physiology of the TCR and since we cannot treat in whole the TCR, the risk factors gain increased importance. The risk factors already known to increase the incidence of TCR include: (i) hypercapnia; (ii) hypoxemia; (iii) light general anesthesia; (iv) age (more pronounced in children); (v) the nature of the provoking stimulus (stimulus strength and duration); and (vi) drugs. Drugs known to increase the TCR include: (i) potent narcotic agents (sufentanil and alfentanil); $; 22,23]$ (ii) beta-blockers; and (iii) calcium channel blockers. ${ }^{[24]}$ Narcotics may augment vagal tone through their inhibitory action on the sympathetic nervous system. ${ }^{[1,25-27]}$ Beta-blockers reduce the sympathetic response of the heart and by so doing, augment the vagal cardiac response resulting in bradycardia. Calcium channel blockers result in peripheral arterial smooth muscle relaxation and vasodilatation causing reduction in blood pressure. In patients undergoing trigeminal manipulations, this worsens the vagal effect that occurs in some patients.

\section{Case Report}

A 60-year-old male patient with a diagnosis of right-sided vestibular schwannoma underwent tumor resection via a retrosigmoid (suboccipital approach) approach. His medical history was significant for long standing hypertension for which he is taking irbesartan (an angiotensin receptor blocker) and a 14-pack-year history of smoking. Otherwise, he has no history of diabetes, cardiac problems, and was not on beta blockers or calcium channel blockers. His baseline MABP was $73.2 \mathrm{~mm} \mathrm{Hg}$ and heart rate was 65 beats per minute. Two hours after skin incision, his MABP dropped to $43.3 \mathrm{~mm} \mathrm{Hg}$ (40.8\% drop from the baseline) and concomitantly, his heart rate dropped to 40 beats per minute (38\% drop from the baseline). Then, the procedure was discontinued; he was given epinephrine and crystalloid fluids. After five minutes, his MABP and heart rate stabilized and the surgical procedure was carried out successfully to the end without any further episodes of TCR. His oxygen saturation was $100 \%$ and no hypercarbia occurred. The postoperative course was uneventful. 


\section{Clinical significance of the trigeminocardiac reflex and why it should be treated}

Most authors recognized that the TCR is a transient response to the trigeminal nerve manipulation in its extra or intracranial course which subsides with cessation of the stimulus. But, in the most serious forms of severe bradycardia and asystole, administration of vagolytic agents is warranted in addition to cessation of the stimulus. Rath et al. reported a case of asystole occuring in a patient who was undergoing percutaneous retrogasserian glycerol rhizolysis for trigeminal neuralgia. ${ }^{[28]}$ Immediately after injection of anhydrous glycerol, the patient became unresponsive, the pulse became impalpable, blood pressure unrecordable, the ECG showed asystole, and had a respiratory arrest. The patient regained consciousness and heart rate and blood pressure returned to normal after 30 seconds with oxygen and IV atropine. ${ }^{[28]}$ Prabhakar et al. also reported a case of sudden asystole without prior bradycardia which occurred during surgery for cerebellopontine angle tumor. ${ }^{[29]}$ This case was just managed by cessation of the manipulation without administration of vagolytic agents. ${ }^{[30]}$ Fayol et al. also reported a five-year-old boy who was operated for strabismus and possibly died due to OCR which developed on underlying myocarditis. ${ }^{[30]}$ These cases demonstrate the (clinical) importance of the TCR which may range from mild bradycardia which responds to simple cessation of the stimulus to asystole and severe bradycardia requiring additional intervention with vagolytics. In some rare but serious cases, it may lead to death if not detected early and appropriate measures taken.

In addition, hypotension which occurs during the TCR may lead to myocardial and cerebral infarction in those who are at risk for these conditions. It has also been shown that the hypotension may lead to worse outcomes in hearing function in patients operated for vestibular schwannoma compared to those who do not develop the reflex. ${ }^{[18,31]}$ In a prospective study of 100 patients after vestibular schwannoma surgery, Gharabaghi et al. found out that the occurrence of TCR was $11 \% \cdot{ }^{[18]}$ With an overall hearing preservation of $47 \%, 11.1 \%$ of the patients in the TCR group and $51.4 \%$ of those in the nonTCR group, experienced preserved hearing function postoperatively. ${ }^{[18]}$ In addition, in cases involving larger tumors, an intraoperative TCR was associated with a significantly worse postoperative hearing function during vestibular schwannoma surgery suggesting that the hypotension following TCR is - in addition to the tumor size-a negative prognostic factor for hearing preservation in patients undergoing VS surgery. ${ }^{[18]}$ In another study, Schaller et al. compared the occurrence and persistence of tinnitus in patients with and without TCR. ${ }^{[32]}$ Among 36 patients operated for vestibular schwannoma, TCR occurred in $17 \%$ and influenced the occurrence of postoperative ipsilateral tinnitus: The overall incidence of postoperative ipsilateral tinnitus was $22 \%$. A total of $60 \%$ patients in the TCR subgroup and only $17 \%$ of in the nonTCR subgroup experienced ipsilateral tinnitus postoperatively. ${ }^{[32]}$ These studies show that there is a tendency for increased complication rates in patients who developed TCR compared to those without it, again stressing the importance of looking it carefully during neurosurgical and especially skull base surgical procedures.

\section{Management of the Trigeminocardiac Reflex}

There has been a lot of discussion about the best and more effective treatment for TCR. ${ }^{[33-42]}$ It is beyond the scope of this manuscript to discuss all these influences. Without any doubt, application of atropine is not the only modality of treatment, based on physiological knowledge of the reflex and based on clinical experience. To the authors opinion, the first and the most important "management option" for the TCR is to be aware of its potential danger and minimize any mechanical stimulation of the nerve.

According to the clinical experience on this topic, the management of patients with TCR can be classified into the following categories which are illustrated in the flow-chart [Figure 1]:

1. Risk factor identification and modification.

2. Prophylactic treatment with either vagolytic agents or peripheral nerve blocks in case of peripheral

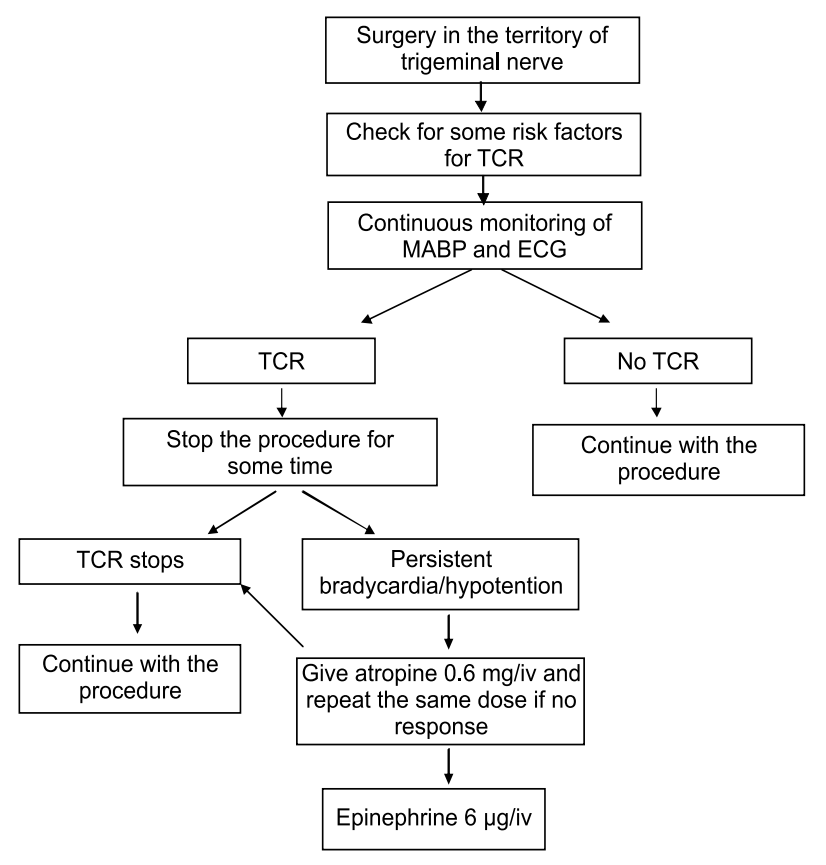

Figure 1: TCR: Management of trigemino-cardiac reflex 
manipulations of the trigeminal nerve.

3. Careful cardiovascular monitoring during anesthesia especially in those with risk factors for TCR.

4. Treatment of the condition when it occurs:

i. cessation of the manipulation, and;

ii. administration of vagolytic agents or adrenaline.

The risk of TCR should be considered in any neurosurgical intervention, especially at the skull base. If any mechanical stimulation to the trigeminal nerve is necessary, which is a rather "robust" nerve, should be as gentle as possible. If working in the vicinity of the nerve or its branches, the anesthesiologist should be notified by the surgeon. Continuous intraoperative monitoring of hemodynamic parameters has been shown to allow the surgeon to interrupt surgical maneuvers immediately upon the occurrence of TCR. This technique has been proven sufficient in most cases for the heart rate and the arterial blood pressure to return to normal levels without the necessity of additional anticholinergic medication. Following this strategy, an uneventful further intraoperative and postoperative course may be achieved. However, the intraoperative reaction of the surgeon to the TCR may be too late to prevent postoperative neurological deficits under certain circumstances. ${ }^{[33,34]}$

If controlled arterial hypotension is planned, the prophylaxis of TCR is better accomplished with local anesthetic infiltration or block of the nerve(s) which convey afferent stimuli. Shende $e t$ al. studied the efficacy of peribulbar block with bupivacaine in patients operated for retinal detachment. ${ }^{[35]}$ They collected 60 patients who were randomly assigned to receive either bupivacaine or IV morphine and studied the incidence and severity of the OCR. Apart from significantly reducing the incidence of OCR (30\% vs. $70 \%$ ), peribulbar bupivacaine also attenuated the severity of the reflex. ${ }^{[35]}$ Gupta et al. studied the effect of peribulbar block in comparison to topical application of local anesthetic in children scheduled for strabismus surgery. They found out that the incidence and severity of OCR intraoperatively was significantly reduced in children who received a peribulbar block. ${ }^{[36]}$ Misurya et al. studied the effectiveness of prophylactic intravenous atropine sulphate which blocks the peripheral muscarinic receptors at the heart and retrobulbar xylocaine hydrochloride, which blocks the conduction at ciliary ganglion on the afferent limb of OCR. In this study, both atropine and retrobulbar xylocaine reduced the rate of OCR to $10-20 \%$. But, when both methods were used together, they were able to completely suppress the OCR. ${ }^{[37]}$

If there is no contraindication to intravenous anticholinergics, atropine and/or glycopyrrolate IV may be used to partially prevent a TCR. ${ }^{[38]}$ Hunsley et al. evaluated the efficacy of IV atropine and glycopyrrolate in the prevention of the OCR in children operated for strabismus. They tested different doses of the two drugs, glycopyrrolate 5 and $7.5 \mu \mathrm{g} / \mathrm{kg}$ and atropine 10 and $15 \mu \mathrm{g} / \mathrm{kg}$. Overall, there is a reduction in the rate of bradycardia to $23.8 \%$ to $33.3 \%{ }^{[39]}$ But, they noticed that even higher doses of the two drugs, atropine $15 \mathrm{mg} / \mathrm{kg}$ and glycopyrrolate $7.5 \mathrm{mg} / \mathrm{kg}$ i.v., given $5 \mathrm{~min}$ before induction of anesthesia, are not sufficient to protect completely against the OCR in children.

In a study done to evaluate the efficacy of IV or IM vagolytic agents (atropine and glycopyrrpolate), in children undergoing squint surgery, Mirakhur et al. evaluated them in a controlled study and found out that the administration of the anticholinergic agents in both the IV and the IM forms may decrease the occurrence of the OCR. ${ }^{[40]}$ The overall frequency was approximately $40 \%$ (62 of 160 patients), but was $90 \%$ in those patients who did not receive anticholinergic drugs. ${ }^{[40]}$ The authors concluded that, administration of anticholinergic drugs, even by the IM route, decreased the frequency, and glycopyrrolate $10 \mu \mathrm{g}$ per $\mathrm{kg}$ being the most efficacious by this route. ${ }^{[40]}$

Intramuscular administration of anticholinergics has shown to be ineffective in preventing the TCR. ${ }^{[29,43]}$ The use of atropine is, nowadays, questioned because cholinergic blockage reduces but does not totally prevent either bradycardia or hypotension in animals. ${ }^{[41]}$ Another reason is that, a trigeminal depressor response includes both activation of vagal cardioinhibitory fibres and inhibition of adrenergic vasoconstriction as demonstrated after electrical stimulation of the spinal trigeminal tract and trigeminal nuclear complex. In addition, atropine may cause serious cardiac arrhythmias itself, especially when halothane is the primary anaesthetic agent and hence the dose must be carefully chosen. ${ }^{[42]}$

Prabhakar et al. reported a 48-year-old female who developed severe bradycardia and hypotension during craniotomy for parietal convexity meningioma; she was unresponsive to atropine and successfully managed with epinephrine. ${ }^{[4]}$ The action of adrenaline is to increase peripheral resistance via alpha-1 adrenoceptor vasoconstriction, so that blood is shunted to the body's core, and the alpha-1 adrenoceptor response which is to increase cardiac rate and output. ${ }^{[4]}$ This important case report underscores the fact that TCR may be refractory to atropine and other vagolytics and may rather need to be managed with epinephrine. ${ }^{[4]}$

In general and with special reference to our case reported here, the treatment of TCR deserves more attention. If 
a TCR is elicited, the surgeon must stop the stimulus and wait until the pulse recovers its normal rhythm. Occurrence of the TCR corresponds to the intensity of the mechanical stimulation on the trigeminal pathway. Abrupt and sustained traction is more likely to evoke the TCR than smooth and gentle manipulations. ${ }^{[34,45-47]}$

\section{Conclusion}

In the present paper, we illustrated the clinical relevance of the TCR and discussed its management. The most important aspects of management which were detailed above are: (i) awareness of its possible occurrence in every patient undergoing head surgery (as there exist no identified risk factors); (ii) prophylactic peripheral nerve block in some type of surgeries (for example, strabismus surgery); (iii) avoidance of traction and gentle manipulation around the nerve, if any necessary intraoperatively; (iv) interaction between surgeon and anethesiologists; (v) careful and continuous monitoring of the heart rate and blood pressure to detect its occurrence; (vi) cessation of the mechanical stimulus upon recovery of pulse rate and arterial blood pressure; (vii) in severe cases of bradycardia and asystole, administration of vagolytic agents such as atropine; (viii) if unresponsive to atropine, epinephrine administration may be considered as ultima ratio.

Further anatomical studies may help to describe the reflex arc in more detail on the one hand and to develop more precise prophylactic treatment options on the other hand.

\section{References}

1. Schaller B, Probst R, Strebel S, Gratzl O. Trigeminocardiac reflex during surgery in the cerebellopontine angle. J Neurosurg 1999;90:215-20.

2. Schaller B. Trigeminocardiac reflex: A clinical phenomenon or a new physiological entity? J Neurol 2004;251:658-65.

3. Schaller B, Cornelius JF, Prabhakar H, Koerbel A, Gnanalingham K, Sandu N, et al. Trigemino-Cardiac Reflex Examination Group (TCREG) The trigeminocardiac reflex: An update of the current knowledge. J Neurosurg Anesthesiol 2009;21:187-95.

4. Kratschmer F. Ueber Reflexe von der Nasenschleimhaut auf Athmung und Kreislauf. Sber Akad Wiss Wien 1870;62:147-70.

5. Kratschmer F. On reflexes from the nasal mucous membrane on respiration and circulation. Translated by E. Ullmann. Respir Physiol 2001;127:93-104.

6. Widdicombe J. Reflexes from the lungs and airways: Historical perspectives. J Appl Physiol 2006;101:628-34.

7. Ashner B. Über einen bisher noch nicht beschriebenen Reflex, vom Auge auf Kreislauf und Atmung. Verschwinden des Radialispulses bei Druck auf das Auge. Wien Klin Wochenschr 1908;21:1529-30.

8. Dagnini G. Interno ad un reflesso provocato inalcuni emplegica collo stimolo della come e colla pressione sul bulbo oculare. Bull Sci Med (Bologna) 1908;8:380.

9. Schaller BJ, Filis A, Buchfelder M. Trigemino-cardiac reflex in humans initiated by peripheral stimulation during neurosurgical skull-base operations. Its first description. Acta Neurochir (Wien) 2008;150:715-8.

10. Ohshita N, Nakajo N, Takemura M. Characteristies of the trigeminal depressor response in cats. J Neurosci Res 2004;76:891-901.
11. Schaller BJ, Buchfelder M. Trigemino-cardiac reflex in skull base surgery: From a better understanding to a better outcome? Acta Neurochir (Wien) 2006;148:1029-31.

12. Alexander JP. Reflex disturbances of cardiac rhythm during ophthalmic surgery. Br J Ophthalmol 1975;59:518-24.

13. Loewinger J, Cohen M, Levi E. Bradycardia during elevation of a zygomatic arch fracture. J Oral Maxillofac Surg 1987;45:710-1.

14. Barnard NA, Bainton R. Bradycardia and the trigeminal nerve. J Craniomaxillofac Surg 1990;18:359-60.

15. Roberts RS, Best JA, Shapiro RD. Trigeminocardiac reflex during temporomandibular joint arthroscopy: Report of a case. J Oral Maxillofac Surg 1999;57:854-6.

16. Shearer ES, Wenstone R. Bradycardia during elevation of zygomatic fractures. A variation of the oculocardiac reflex. Anaesthesia $1987 ; 42: 1207-8$.

17. Apt L, Isenberg S, Gaffney WL. The oculocardiac reflex in strabismus surgery. Am J Ophthalmol 1973;76:533-6.

18. Gharabaghi A, Koerbel A, Samii A, Kaminsky J, von Goesseln H, Tatagiba M, et al. The impact of hypotension due to the trigeminocardiac reflex on auditory function in vestibular schwannoma surgery. J Neurosurg 2006;104:369-75.

19. Schaller B. Trigemino-cardiac reflex during transsphenoidal surgery for pituitary adenomas. Clin Neurol Neurosurg 2005; 107:468-474

20. Schaller B. Trigeminocardiac reflex during microvascular trigeminal decompression in cases of trigeminal neuralgia. J Neurosurg Anesthesiol $2005 ; 17: 45-8$.

21. Filis A, Schaller B, Buchfelder M. Trigeminocardiac reflex in pituitary surgery. A prospective pilot study. Nervenarzt 2008;79:669-75.

22. Rivard JC, Lebowitz PW. Bradycardia after alfentanil-succinylcholine. Anaesth Analg 1988;76:907.

23. Starr NJ, Sethna DH, Estafanos FG. Bradycardia and asystole following rapid administration of sufentanil with vecuronium. Anesthesiology 1986;64:521-3.

24. Schmeling WT, Kampine JP, Warltier DC. Negative chronotropic actions of sufentanil and vecuronium in chronically instrumented dogs pretreated with propanolol and/or diltiazem. Anaesth Analg $1989 ; 66: 4-14$.

25. Blanc VF, Hardy JF, Milot J, Jacob JL. The oculocardiac reflex: A graphic and statistical analysis in infants and children. Can Anaesthet Soc J 1983;30:360-9.

26. Lang S, Lanigan DT, van der Wal M. Trigeminocardiac reflexes: Maxillary and mandibular variants of the oculocardiac reflex. Can J Anaesth 1991;38:757-60.

27. Moonie GT, Ress EL, Elton D. The oculocardiac reflex during strabismus surgery. Can Anaesthet Soc J 1964;11:621.

28. Rath GP, Dash HH, Prabhakar H, Pandia MP. Cardiorespiratory arrest during trigeminal rhizolysis. Anaesthesia 2007;62:971-2.

29. Prabhakar H, Anand N, Chouhan RS, Bithal PK. Brief report of special case: Sudden asystole during surgery in the cerebellopontine angle. Acta Neurochir (Wien) 2006;148:699-700.

30. Fayon M, Gauthier M, Blane VF, Ahronheim GA, Michaud J. Intraoperative cardiac arrest due to the oculocardiac reflex and subsequent death in a child with occult Epstein-Barr Virus myocarditis. Anesthesiology 1995;83:622-4

31. Schaller BJ. Trigeminocardiac reflex. J Neurosurg 2007;107:243.

32. Schaller BJ, Rasper J, Filis A, Buchfelder M. Difference in functional outcome of ipsilateral tinnitus after intraoperative occurrence of the trigeminocardiac reflex in surgery for vestibular schwannomas. Acta Neurochir (Wien) 2008;150:157-60.

33. Gharabaghi A, Acioly de Sousa MA, Tatagiba M. Detection and prevention of the trigeminocardiac reflex during cerebellopontine angle surgery. Acta Neurochir (Wien) 2006;148:1223.

34. Koerbel A, Gharabaghi A, Samii A, Gerganov V, von Gösseln H, Tatagiba M, et al. Trigeminocardiac reflex during skull base surgery: Mechanism and management. Acta Neurochir (Wien) 2005;147:727-33.

35. Shende D, Sadhasivam S, Madan R. Effects of peribulbar bupivacaine as an adjunct to general anesthesia on peri-operative outcome following retinal detachment surgery. Anaesthesia 2000;55:970-5.

36. Gupta N, Kumar R, Kumar S, Sehgal R, Sharma KR. A prospective randomised double blind study to evaluate the effect of peribulbar 
block or topical application of local anesthesia combined with general anesthesia on intra-operative and postoperative complications during paediatric strabismus surgery. Anaesthesia 2007;62:1110-3.

37. Misurya VK, Singh SP, Kulshrestha VK. Prevention of oculocardiac reflex (O.C.R) during extraocular muscle surgery. Indian J Ophthalmol 1990;38:85-7.

38. Blane VF. Trigeminocardiac reflexes. Can J Anesthesia 1991;38:696-9.

39. Hunsley E, Bush GH, Jones C.J. A study of Glycopyrrolate and Atropine in the suppression of the oculocardiac reflex in strabismus surgery in children. Br J Anaesth 1982;54:459-64.

40. Mirakhur RK, Jones C.J, Dundee JW, Archer DB. I.M or I.V atropine or glycopyrrolate for the prevention of oculocardiac reflex in children undergoing squint surgery. Br J Anaesth 1982;54:1059.

41. Schaller B, Sandu N, Filis A, Buchfelder M. Peribulbar block of topical application of local anesthesia combined for paediatric strabismus surgery. Anaesthesia 2008;63:1142-3.

42. Schaller BJ, Weigel D, Filis A, Buchfelder M. Trigemino-cardiac reflex during transsphenoidal surgery for pituitary adenomas: Methodological description of a prospective skull base study protocol. Brain Res
2007;1149:1169-75.

43. Prabhakar H, Rath GP, Arora R. Sudden cardiac standstill during skin flap elevation in a patient undergoing craniotomy. J Neurosurg Anesthesiol 2007;19:203-4.

44. Prabhakar H, Ali Z, Rath GP. Trigemino-cardiac reflex may be refractory to conventional management in adults. Acta Neurochir (Wien) 2008;150:509-10.

45. Schaller B, Filis A, Buchfelder M. Cardiac autonomic control in neurosurgery. Arch Med Sci 2007;4:287-92.

46. Schaller B, Buchfelder M. Trigemino-cardiac reflex: A recently discovered "oxygen-conserving" response? The potential therapeutic role of a physiological reflex. Arch Med Sci 2006;2:3-5.

47. Schaller B, Cornelius JF, Sandu N, Ottaviani G, Perez-Pinzon MA. Oxygen-conserving reflexes of the brain: The current molecular knowledge. J Cell Mol Med 2009;13:644-7.

Accepted on 24-07-09

Source of Support: Nil, Conflict of Interest: None declared.

\section{Author Help: Online submission of the manuscripts}

Articles can be submitted online from http://www.journalonweb.com. For online submission, the articles should be prepared in two files (first page file and article file). Images should be submitted separately.

1) First Page File:

Prepare the title page, covering letter, acknowledgement etc. using a word processor program. All information related to your identity should be included here. Use text/rtt/doc/pdf files. Do not zip the files.

2) Article File:

The main text of the article, beginning with the Abstract to References (including tables) should be in this file. Do not include any information (such as acknowledgement, your names in page headers etc.) in this file. Use text/rtf/doc/pdf files. Do not zip the files. Limit the file size to $400 \mathrm{~kb}$. Do not incorporate images in the file. If file size is large, graphs can be submitted separately as images, without their being incorporated in the article file. This will reduce the size of the file.

3) Images:

Submit good quality color images. Each image should be less than $1024 \mathbf{~ k b ~ ( 1 ~ M B ) ~ i n ~ s i z e . ~ T h e ~ s i z e ~ o f ~ t h e ~ i m a g e ~ c a n ~ b e ~ r e d u c e d ~ b y ~ d e c r e a s - ~}$ ing the actual height and width of the images (keep up to about 6 inches and up to about 1200 pixels) or by reducing the quality of image. JPEG is the most suitable file format. The image quality should be good enough to judge the scientific value of the image. For the purpose of printing, always retain a good quality, high resolution image. This high resolution image should be sent to the editorial office at the time of sending a revised article.

4) Legends:

Legends for the figures/images should be included at the end of the article file. 